\title{
Havacılıkta Kullanılan Elektronik Podun Isıl Kontrolü
}

\author{
${ }^{* 1}$ Muhammed Asım Kesercioğlu, ${ }^{1}$ Abdullah Feyzi Keleş, ${ }^{2,3}$ Nedim Sözbir, ${ }^{1}$ Yusuf Çay \\ ${ }^{1}$ Sakarya Uygulamalı Bilimler Üniversitesi, Teknoloji Fakültesi, Makine Mühendisliği, Sakarya, Türkiye, \\ ${ }^{2}$ Sakarya Üniversitesi, Mühendislik Fakültesi, Makine Mühendisliği, Sakarya, Türkiye \\ ${ }^{3}$ TÜBITTAK MAM, Gebze, Kocaeli, Türkiye
}

\section{Özet}

Pod, havacılıkta farklı görevler için kullanılmak üzere içerisinde çeşitli faydalı yükler bulunduran kutudur. Bu faydalı yükler elektronik ekipmanlardan oluşurken; keşif, arazi gözetleme, hedefleme, kızılötesi görüş, navigasyon gibi görevlerde kullanılmak üzere pod içerisine yerleştirilir. Pod; ön, orta ve arka olmak üzere üç ana bölümden oluşur.

Podun içerisinde en önemli kısım 1sıl kontrol sistemidir. Podun içerisinde bulunan elektronik ekipmanlar belirlenmiş sıcaklık değerleri arasında olmalıdır. Tüm elektronik cihazlar gibi podun içerisindeki elektronik ekipmanlar da belli miktarda 1sı yaymaktadır. Yayılan bu 1sı bir soğutma sistemi ile alınmadığında elektronik ekipmanlara zarar vererek çalışma performanslarının düşmesine ya da tamamen çalışmamalarına neden olmaktadır. Bu sebeple 1sı yayan elektronik ekipmanlardan isının alınması gerekmektedir. Yapılan soğutma sonucunda da istenilen şartlar altında elektronik podun çalışması sağlanmaktadır. Podun isıl kontrolünün en verimli şekilde yapılabilmesi için isıl kontrol sisteminin, podun orta kısmına yerleştirilmesi gerekmektedir. Ekipmanların isıl kontrolü; direk ram havasının kullanıldığı hava çevrimli sistem ile, buhar çevrimli soğutma sistemiyle veya bu ikisinin birlikte olduğu hibrit sistem ile yapılmaktadır.

Bu çalışmada havacılıkta kullanılan ve içerisindeki ekipmanların $5000 \mathrm{~W}$ 1sı yaydığı elektronik podun soğutulması amacıyla hava çevrimini kullanarak çalışan bir ısıl kontrol sistemi tasarlanmıştır. Isıl kontrol için ram havası kullanılan hava soğutmalı sistem kullanılmıştır. Bu sistem, çalışmak için herhangi bir elektrik gücü almaz, gereken enerji uçağın uçuşu esnasında ram girişinden alınan ram havasının tahrik etmesi ile sistem çalışır. Ram havası ile çalışan sistem; ram havası girişi, türbin, kompresör, pompa ve 1S1 değiştiricisinden oluşmaktadır. Yapılan ısıl kontrol ile farklı uçak hızları ve yüksekliklerinde, soğuk ve sıcak günlerde poda giren ve çıkan havanın sıcaklık değerleri, podun içerisindeki elektronik ekipmanların sıcaklık değerleri incelenmiş ve kullanılan hava çevrimi ile çalışan sistemin, incelenen şartlar altında elektronik ekipmanları soğutarak uygun çalışmalarını sağladığı gözlemlenmiştir.

Anahtar Kelimeler: Elektronik pod, Soğutma, Isıl kontrol

\begin{abstract}
There are some electronic devices for use in aircraft within the electronic pod. Electronic equipments in the pod must be between the given temperature values. This equipments emits heat. If the radiated heat is not taken with a cooling system, it prevents the electronic equipment to work. For this reason, heat dissipating equipment must be cooled. As a result of the cooling process, it is ensured that the electronic pod works under the desired conditions.
\end{abstract}

In this study, an air cycle-operated cooling system is designed for the cooling of the electronic pod, which is used in airplanes and which supplies $5000 \mathrm{~W}$ of heat inside the equipment. Air cooled system is used for thermal control. The system does not receive any electrical power from the aircraft, but instead operates the system by driving the ram air received from the ram input during the flight of the required

*Corresponding author: Address: Faculty of Technology, Department of Mechanical Engineering Sakarya University of Applied Sciences, 54187, Sakarya TURKEY. E-mail address: mkesercioglu@ sakarya.edu.tr, Phone: $+902646160291$ 
energy aircraft. The system which driven by ram air is contains ram air inlet, turbine, compressor, heat exchanger and pump.

The temperature values of the electronic equipment, air inlet and outlet of the pod were examined at different elevations and aircraft speeds for the hot and cold days. It is determined that the air-cooled systems can be used.

\section{Giriş}

Elektronik pod, uçaklarda farklı görevler için kullanılacak farklı ekipmanlar bulunduran kutudur. Podlar uçakların genelde altına uçağın uygun başka bir yerine monte edilirler. İçlerinde bulunan ekipmanlar genellikle keşif, arazi gözetleme, hedefleme, kızılötesi görüş, navigasyon ekipmanları olarak siralanır.

Elektronik podun içerisinde bulunan elektronik ekipmanlar çalışırken belli miktarda 1sı üretirler. Aynı zamanda bahsedilen ekipmanların, üreticiler tarafından belirlenen çalışma ve depolama sıcaklıkları vardır. Ekipmanlardan yayılan 1sı podun içerisindeki 1sıyı arttırır. Bu 1sının bir sistem yardımıyla poddan atılması gerekmektedir. Atılmadığı takdirde ekipmanlar çalışamaz ve görevini yerine getiremezler. Bunun yanında elektronik ekipmanların, belirlenen sıcaklık aralığının altındaki soğuk havalarda da ekipmanlar çalışmamaktadır. Dolayısıyla elektronik ekipmanların belirtilen sıcaklık aralı̆̆ında çalışmasını sağlamak amacıyla optimum ısıl kontrolün yapılması gerekmektedir. Bahsedilen 1sıl kontrol günümüzde; direk ram havası kullanılan hava çevrimli soğutma sistemi ile, buhar çevrimli soğutma ile veya bu ikisinin birlikte bulunduğu hibrit bir sistem ile gerçekleştirilmektedir. [1]

Price ve arkadaşları (2003) bir uçağın podunun içine monte edilmiş elektronik ekipmanın ısıl kontrolünü zorlu bir mücadele olarak betimlemişlerdir. Bunun yanında podun kullanılacağg göreve, ekipmanların özelliklerine, ortam ve uçuş şartlarına bağlı olarak doğru 1sıl control yönteminin seçilmesinin hayati öneme sahip olduğu vurgulanmıştır. [3]

Elektronik ekipmanların güçlerinin gün geçtikçe artmasıyla birlikte, geleneksel pasif isıl kontrol tekniklerinin eski hale geldiğini ve yeni soğutma tekniklerinin zorunlu hale geldiğini belirten Zhihui Wu ve arkadaşları (2011) farklı yeni teknikler arasında, buhar sıkıştırmalı soğutma sisteminin en ideal sistem olduğunu ortaya koymuştur. Yaptıkları çalışma sonucunda, elektronik ekipmanları soğutmak için minyatür bir buhar sıkıştırmalı soğutma sistemi ortaya konmuştur. [4]

Leitner ve arkadaşlarının 2012 yılında ortaya koyduğu çalışmada, bir hava döngülü soğutma sistemi tasarlanarak üzerinde deneyler yapılmıştır. Makine F-16'da kullanılan bir elektronik podun 
soğutulması amacıyla tasarlanmıştır. Aynı zamanda hava döngülü soğutma sistemi ile buhar çevrimi sistem karşılaştırılarak hava çevrimli sistemin avantajları anlatılmış ve sonuç olarak seçilen sistemin istenilen soğutma performansını sağladığı ortaya konmuştur. [5]

$\mathrm{Bu}$ çalışmada, $5000 \mathrm{~W}$ 1sı yayan elektronik ekipmanların 1sıl kontrolünün yapılması için hava çevrimli bir 1sıl kontrol sistemi tasarlanacaktır ve poda giren ve çıkan havanın sıcaklık değerleri ile elektronik ekipmanların sicaklık değerleri hesaplanacaktır. Bunun sonucunda sistemin uygunluğu ve ekipmanların soğutulmasının bu mümkün olup olmadığı ortaya konulacaktır.

\section{Elektronik Pod Sistemi}

Uçakların fonksiyonelliğini arttıran ve farklı donanımlarla donatan podlar için bazı sınırlamalar vardır. Bu sınırlamalar boyut, ağırlık, elektrik tüketimi limiti, uygun çalışma sıcaklık aralığ şeklinde sıralanabilir [6]. Dolayısıyla uçakta kullanılmak üzere üretilen podun tasarımı bu sinırlamalar göz önünde bulundurularak yapılmalıdır.

Bir elektronik pod Şekil 1'de gösterildiği gibi tasarlanarak uçağa eklenmektedir ve genel itibariyle yine Şekil 1'de belirtilen ekipmanlardan oluşmaktadır. Çeşitli ekipmanlarla donatılan podlar ile birlikte uçakların kullanım ömrü ve kabiliyetleri arttırılmaktadır.

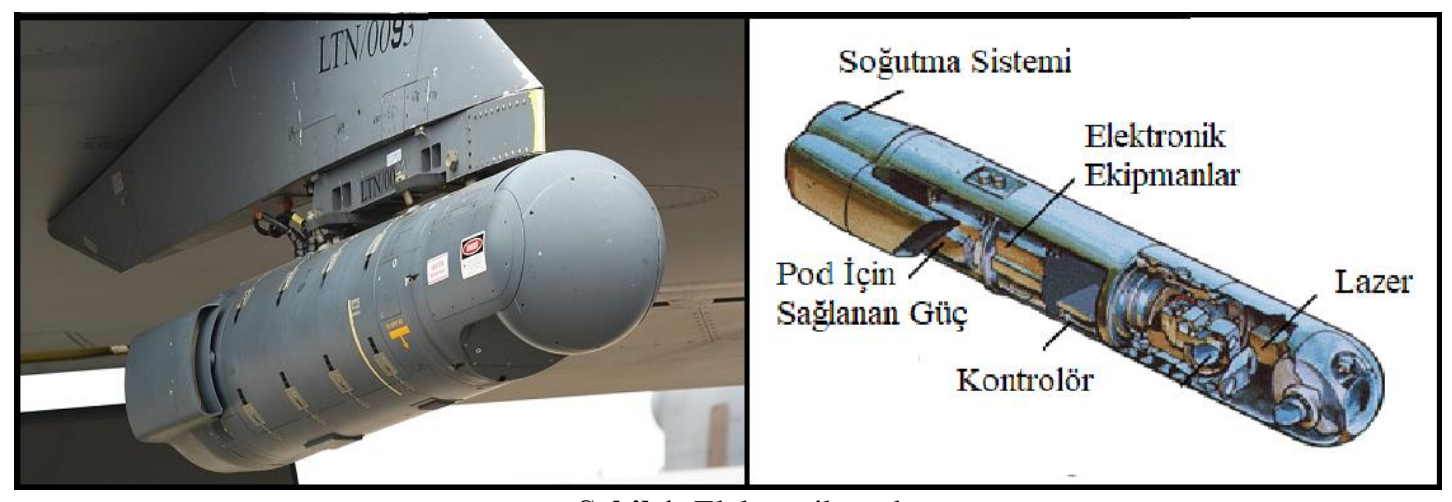

Şekil 1. Elektronik pod

Podun bahsedilen avantajlarının yanında bir de dezavantajı bulunmaktadır. Podun içerisinde bulunan elektronik ekipmanların, üreticilerin tanımladığı uygun çalışma ve depolama sıcaklık aralıklarında olması sağlanmalıdır. Eğer sıcaklık değerleri belirtilen aralıkların dışına çıktığı takdirde ekipmanlar zarar görerek çalışamaz hale gelir ve yeterli performansı sağlayamaz. Bununla birlikte her elektronik ekipman gibi podda bulunan ekipmanlar da çalıştıkları sırada belli miktar 1sı üretir ve ürettikleri bu 1sı sonucunda sıcaklıkları artar. Sonuç olarak ekipmanların istenilen sıcaklık aralığında tutmak amacıyla ısının bir ısıl kontrol sistemiyle dışarı atılması gerekmektedir.

\subsection{Podlarda Kullanulan Isıl Kontrol Sistemleri}

Podun ısıl kontrolü için kullanılacak sistemin seçimi, pod içindeki ekipmanların durumu ve çevre 
şartları göz önünde bulundurularak yapılır. Direk ram havası kullanılan hava çevrim makinesi çalışmaya başlamak için dış güç istemeden ram havasının system tarafından yakalanmasıyla çalışan bir sistemdir. Sisteme giren ram havasının sıcaklığı, uçağın hızının karesiyle artar ve bunun sonucunda da basınç artar. Dolayısıyla sistemin verimli çalışması için uçak hızının yüksek olması gerekmektedir. Bu sebeple uçağın hızının Mach altı olduğu durumlarda sistemin tam anlamıyla çalışması ve performans sağlaması olanaksızdır. Ayrıca uçağın belli bir yükseklikte uçmayıp deniz seviyesinde olarak sistemin çalıştığı durumlarda sistemin çalışması için gereken ram havası olmayacak ve sistem çalışmayacaktır. Böyle durumlarda soğutma amacıyla uygun bir fan kullanımı mümkündür.

Podun 1sıl kontrolü için direk ram havası kullanılan sistemin dışında ikinci bir yol buhar çevrimli sistemdir. Sistemin ideal buhar sıkıştırmalı soğutma çevrimine göre çalışmaktadır. Uçağın düşük Mach hızlarında verimli çalışan ve yüksek soğutma performansı vermektedir. Bu sistemin başlangıcı için büyük bir güç gerekmektedir ve bu ciddi bir dezavantajdır. Diğger bir olumsuz tarafı ise; sistemdeki soğutucu akışkanın kullanım sınırlamasıdır. Buhar çevrimli sistemde kullanılan soğutucu akışkan olan kloroflorokarbonun, ozon delinmesinde payı büyük olduğu için 2006 yılı içerisinde kullanımı sınırlı hale getirilmiş, 2008 yılında ise kullanımı yasaklanmıştır. Kloroflorokarbon dışında farklı akışkanlar sistemde kullanılabilir olsa da sistem verimini \%20 oranına kadar düşürmektedir. Buhar çevrimli sistemin bakımı oldukça zor ve hava çevrimli sisteme göre maliyeti daha yüksektir. Aynı zamanda sistemin elektrik tüketiminin yüksek olması sonucunda soğutma performansı elektrik gücü ile doğrudan bağlantılı ve sınırlıdır.

Üçüncü yol hibrit sistem ise, diğer iki sistemin (Hava çevrimi ve buhar çevrimi) birleşiminden oluşan sistemdir. Hava çevrimli ve buhar çevrimli sistemlerin bir uçağın tüm uçuş zarflarında tek başlarına yetmediği şartlarda ya da yeterli soğutmanın sağlanamadığı durumlarda kullanılmaktadır. Burada uçak eğer düşük Mach hızlarında uçuyor ve hava çevrimi ile soğutma yeterli oranda sağlanamıyorsa buhar çevrimli sistem devreye girerek soğutmayı gerçekleştirmektedir. Sistemin uçuş zarfına göre ve etkili kullanılması en belirgin avantajdır. Bunun yanında bakımı zor ve maliyeti diğer iki sisteme göre oldukça yüksektir. [7]

\subsection{Hava Çevrimli Sistem}

Soğutucu olarak uçak tarafindan ram girişi ile yakalanan ram havası kullanılan hava çevrimli sistem, 1900'lerin ortalarından itibaren uçakların veya podların ısıl kontrolü için kullanılmaktadır. Sistemi çalıştırmak için dışardan herhangi bir güç verilmesine ihtiyaç bulunmaz, ram girişi atmosferden yakalanan hava tarafından sistem çalıştırılır. Sistem; ram havası girişi, radyal türbin, radyal kompresör, soğutucu akışkan pompası ve 1s1 değiştiricisinden oluşmaktadır. Diğer sistemlerle kıyaslandığında, soğutucu olarak hava kullanılması sebebiyle daha az maliyetli ve bakımı kolaydır. Hava çevrimli sistemin COP değeri 10'dan daha büyük olmasına karşın, buhar çevrimli sistemin COP değeri 1 civarındadır [5]. Bunların yanında çevreye olan zararsızlığı da diğer sistemlerle kıyaslandığında önemli bir artısıdır.

Sistemin çalışma prensibine bakıldığında; uçak belli bir irtifada ve Mach’ta uçarken podun yanına yerleştirilen ram havası girişi vasıtasıyla sisteme atmosferden hava alınır. Ram girişi lüle şeklinde yapılarak iş elde etmek için havanın basıncı ve sıcaklığı arttırılır. Ram girişinden sonra hava, 
türbine gönderilerek atmosfere göre yüksek sıcaklık ve yüksek basınçta olması sebebiyle türbinin çalışması sağlanır. Aynı zamanda türbinin çalışması sonucunda bir mil ile türbine doğrudan bağlı olan kompresör de çalışır. Türbinden çıkan ve sıcaklığıyla basıncı düşen hava soğutmak amacıyla 1sı değiştiricisine alınır. Sistemdeki ısı değiştiricisi, ekipmanlardan gelen sıcak soğutucu akışkanın, türbinden gelen soğuk ram havası ile soğutulması şeklinde çalışmaktadır. Elektronik ekipmanlar alüminyum plakaya bağlı olup plakanın içerisine boruyla giren soğutucu akışkan ile soğutma sağlanır. Isı değiştiricisinde hava, soğutucu akışkanın ısısını alarak, türbinde iş üretilmesi sonucunda kompresöre alınır, sıcaklık ve basınç değerleri burada artarak uçuş yönünün tersinde bulunan çıkıştan atmosfere gönderilir. Bunun yanında, 1sı değiştiricisinde havaya 1sısını vererek soğuyan soğutucu akışkan ekipmanları soğutmak için bir pompa ile ekipmanlara tekrar iletilir. Ram havası sıcaklığının $10{ }^{\circ} \mathrm{C}$ 'nin altında olduğu durumlarda bir valf ile bypass yapılarak hava doğrudan 1s1 değiştiricisine gönderilir ve 1sı değiştiricisinden sonra da kompresöre girmeden sistemden atılır. Bu sistem yoluyla istenilen durumlar altında ekipmanların 1sıl kontrolü gerçekleşir [8]. Sistemin büyük olması bir dezavantaj olması sebebiyle 1sı değiştiricisi türbin ve kompresörün bağlı olduğu milin çevresine dairesel şekilde yerleştirilmektedir. Elektronik ekipmanlardan 1sıyı etkin bir şekilde alabilmek için seçilen soğutucu akışkan önemlidir. Burada 1sı çekmeyi etkileyen parametreler; akışkanın kaynama, donma noktaları ve, 1sı geçirgenliği, yoğunluğu ve viskozitesidir [9]. R-236, R-123, R-134 gibi akışkanlar ekipmanların soğutulması amacıyla kullanılmaktadır. [5]

Şekil 2'de elektronik podların içerisinde kullanılan hava çevrimli soğutma sistemi görünmektedir.

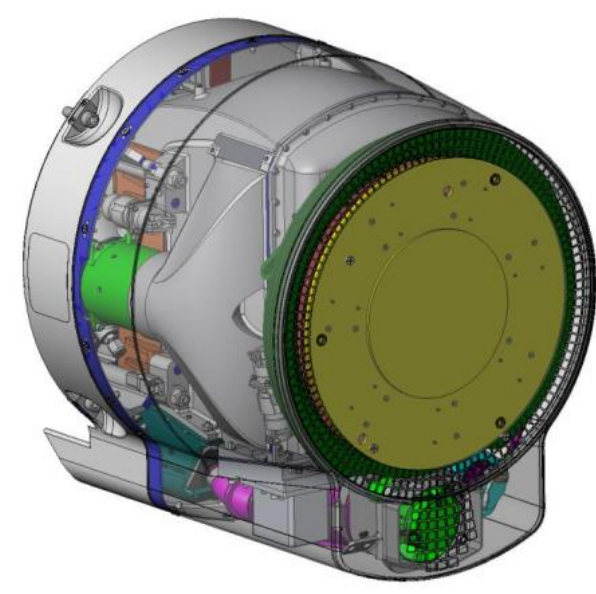

Şekil 2. Hava çevrimli soğutmas sistemi [5]

\subsection{Hesaplamalar}

Bu çalışmada içerisindeki ekipmanların $5 \mathrm{~kW}$ 1sı yaydığı elektronik podun 1sıl kontrolü yapılmıştır. Poddaki elektronik ekipmanların bulunması istenen sicaklık aralığ -10 ile $+85^{\circ} \mathrm{C}$ olarak verilmiştir. Ekipmanları bu değerler arasında tutabilmek amacıyla ısıl kontrol yapılmıştır. Podun kalınlığı 75 santimetre, uzunluğu $3 \mathrm{~m}$ ve yüksekliği 55 santimetredir. Ram havası girişindeki çap 4 santimetredir. Sistemde kullanılacak soğutucu akışkan hexafloropropan (R-236fa) olarak belirlenmiştir. Akışkanın özgül ısı oranı 1.08, doyma basıncı $25^{\circ} \mathrm{C}$ 'de 2.72 bar, $50^{\circ} \mathrm{C}$ 'de 5.84

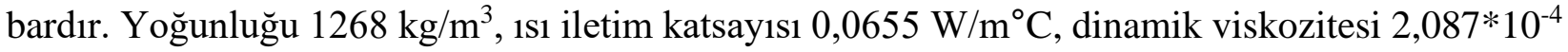


$\mathrm{kg} / \mathrm{m} . \mathrm{s}$ ve Prandtl sayısı 4,1518 olarak alınmıştır. [10] Akışkan 0,025 metre çapındaki boruda 0.7 $\mathrm{m} / \mathrm{s}$ hız ile dolaşarak alüminyum plaka içinde 2 metre uzunluğundaki bölümde akarak soğutmayı gerçekleştirmektedir. Alüminyum plaka uzunluğu 40 santimetre, kalınlığı 1,5 santimetre ve genişliği 30 santimetredir. Ekipman plakası alüminyum plaka ile aynı boyuttadır.

Isıl tasarım ve kontrolde, sistemdeki prosesin matematiksel modelini kolaylaştırmak için bazı fiziki kabuller yapılmıştır. Hava yoğunluğunun sıcaklık ile değişimi yüksek ile değişimine oranla çok az olduğu için, hava yoğunluğu sadece yüksekliğe bağlı fonksiyon olarak kullanılmıştır. Havanın basıncındaki değişim ABD Standart Atmosfer Özelliklerine göre alınmıştır. Hava yoğunluğu 300 metre yükseklikte $1,225 \mathrm{~kg} / \mathrm{m}^{3}$ ve yüksekliğe göre değişimi ABD standartlarına göre alınmıştır [11]. Podun, hava sürtünmesinden kaynaklanana aerodinamik 1sınması, mekanik sürtünmelerden kaynaklanan 1Sı ve verim kayıpları ve boru kayıpları ihmal edildi. Soğutucu akışkanın sitem içerisindeki kütlesel debisi sürekli daima eşittir. Havanın kütle debisi hız ve yüksekliğe bağlı olarak değişmekte olup belli yükseklik ve hızda sistem içerisinde değişmemektedir. Soğutucu akışkanın ısı değiştiricisine giriş ve çıkış sıcaklıkları sırasıyla $47^{\circ} \mathrm{C}$ ve $40^{\circ} \mathrm{C}$ 'dir. Alüminyum plakanın ssı iletim katsayıs $167 \mathrm{~W} / \mathrm{m}^{\circ} \mathrm{C}$ ve ekipmanların ısı iletim katsayısı $386 \mathrm{~W} / \mathrm{m}^{\circ} \mathrm{C}$ ' dir. Elektronik podun çevresi adyabatiktir [12]. Yükseklik ile değişen ortam sıcaklıkları Şekil 3'te gösterilen askeri standartlara göre seçilmiştir [13].

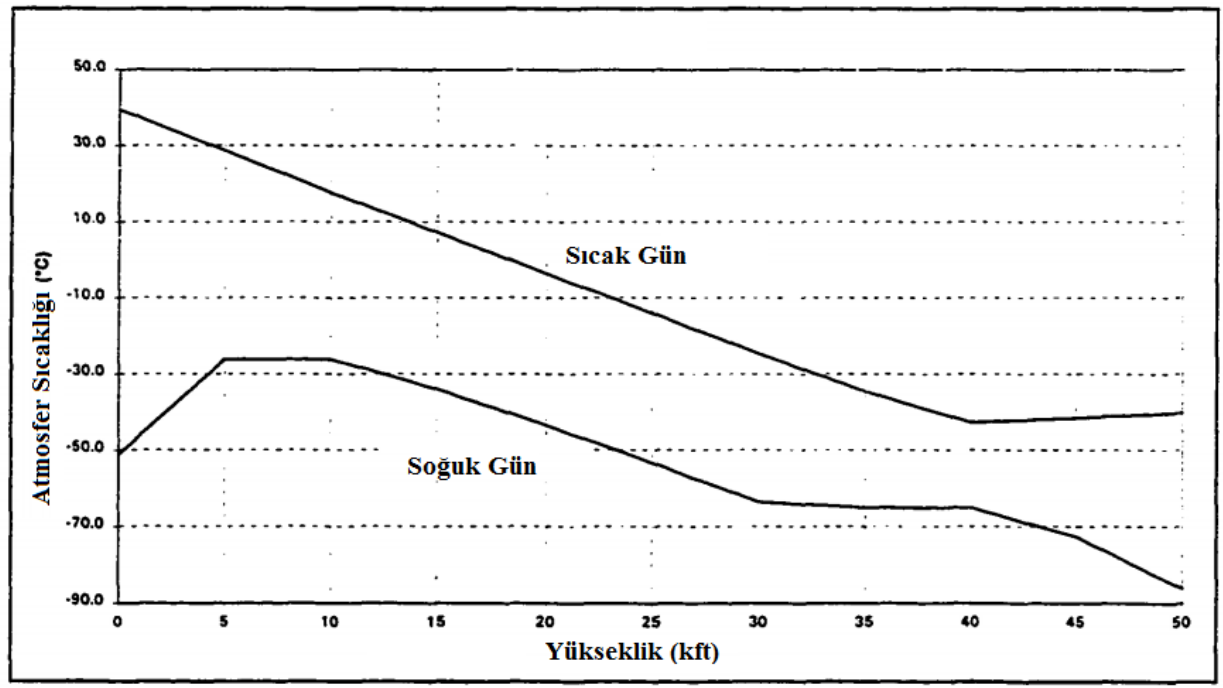

Şekil 3. Sıcak ve soğuk günler için yüksekliğe bağlı atmosfer sıcaklığı

Ram havası girişinden sisteme giren havanın kütle debisi Denklem 2.1 ile hesaplanır.

$m_{\text {hava }}=\rho_{\text {hava }} \cdot A_{\text {kesit }} \cdot V_{u c ̧ a k}$

Uçağın hızı Denklem 2.2 ile hesaplanır. C ses hızı, $M_{\infty}$ Mach sayısıdır.

$V_{u c ̧ a k}=M_{\infty} \cdot C$ 
Lüle şeklindeki ram girişinden sisteme dahil olan havanın sıcaklığg Denklem 2.3 ile sıcaklığ arttırılır, izantropik sıkıştırma ile de Denklem 2.4'teki şekilde basıncı artırılır. Denklem 2.5 ile özgül ısılar oranı k hesaplanır. $T_{\infty}$ atmosfer havası sıcaklığı, $T_{1}$ ram çıkışındaki hava sıcaklığı, $P_{\infty}$ atmosfer basıncı, , $P_{1}$ ram çıkışındaki hava basıncıdır.

$$
\begin{aligned}
& T_{1}=T_{\infty}\left(1+\frac{k-1}{2} \cdot M_{\infty}{ }^{2}\right) \\
& P_{1}=P_{\infty}\left(\frac{T_{1}}{T_{\infty}}\right)^{\frac{k}{k-1}} \\
& k=\frac{C_{P}}{C_{v}}
\end{aligned}
$$

Hava ram girişinden sonra $T_{1}$ sıcaklığında ve $P_{1}$ basıncında türbine girer ve izantropik genişleme ile basıncı azaltılır. Türbin çıkış sıcaklı̆̆ı ve basıncı sırasıyla Denklem 2.6 ve Denklem 2.7 ile hesaplanır. $P_{r}$ sıkıştırma oranı, $T_{2}$ türbin çıkışındaki hava sıcaklığı, $P_{2}$ türbin çıkışındaki hava basincidir.

$$
\begin{aligned}
& T_{2}=\frac{T_{1}}{\left(\frac{P_{1}}{P_{2}}\right)^{\frac{k-1}{k}}} \\
& P_{2}=P_{r, \text { türbin }} \cdot P_{1}
\end{aligned}
$$

Türbinden çıkan hava $T_{2}$ sıcaklığında ve $P_{2}$ basıncında 1 sı değiştiricisine girer ve havaya ekipmanlardan gelen soğutucu akışkandan sabit basınçta 1sı geçişi olur (Denklem 2.8). Isı geçişi sonucunda havanın sıcaklığı Denklem 2.9 ile hesaplanır. $\dot{Q}$ elektronik ekipmanlardan gelen 1s1 miktarı, $C_{P}$ sabit basınç altında havanın özgül 1sısı, $T_{3}$ 1sı değiştiricisinden çıkan hava sıcaklığı, $P_{3}$ 1sı değiştiricisinden çıkan hava basıncıdır.

$$
\begin{aligned}
& P_{3}=P_{2} \\
& T_{3}=\frac{\dot{Q}}{\dot{m} \cdot C_{P}}+T_{2}
\end{aligned}
$$

Isı değiştiricisinde havanın sıcaklığı artarak sıkıştırma oranı türbin ile aynı olan adyabatik kompresöre girer ve izantropik sıkıştırma ile basıncı artar. Kompresörden sonra hava uçak gidiş yönüne ters bir çıkıştan atmosfere gönderilir. Kompresörün çıkışındaki hava basıncı Denklem 2.10 ile, kompresör çıkışındaki havanın sıcaklığı Denklem 2.11 ile hesaplanır. $P_{3}$ girişindeki hava basıncı, $P_{4}$ kompresör çıkışındaki hava basıncı, $T_{3}$ kompresör girişindeki hava sıcaklı̆̆ı, $T_{4}$ kompresör çıkışındaki hava sıcaklığıdır.

$$
P_{4}=P_{r, \text { kompresör }} \cdot P_{3}
$$


$T_{4}=T_{3}\left(\frac{P_{4}}{P_{3}}\right)^{\frac{k-1}{k}}$

Elektronik ekipmanları soğutan akışkanın dolaştığ ikinci çevrimde, soğutucu akışkan

ekipmanlardan 1sıyı alır ve sıcaklığı yükselir, daha sonra 1sı değiştiricine girer. Isı değiştiricisine gelen hava ile soğutucu akışkandan ısı çekilerek sıcaklığı düşürülür. Soğutucu akışkanın ekipmanlara giriş ve çıkışı arasındaki sıcaklık farkı Denklem 2.12 ile hesaplanır. $T_{1, R}$ soğutucu akışkanın ekipmanlara giriş sıcaklığı, $T_{2, R}$ soğutucu akışkanın ekipmanlardan çıkış sıcaklığı, $Q_{\text {ekıpman }}$ soğutucu akışkanın ekipmanlardan çektiği 1sı, $C_{P, R}$ soğutucu akışkanın sabit basınçta özgül ısısı, $m_{R}$ soğutucu akışkanın kütle debisidir.

$\left(T_{1, R}-T_{2, R}\right)=\frac{Q_{\text {ekıpman }}}{m_{R} C_{P, R}}$

V soğutucu akışkanın hızı, D aktığı borunun çap1, $\rho_{R}$ yoğunluğu, $\mu$ dinamik viskozitesi olmak üzere soğutucu akışkanın Reynolds sayısı Denklem 2.13 ile hesaplanır.

$R e=\frac{\rho_{R} \cdot V \cdot D}{\mu}$

Re Reynolds sayısı, Pr Prandtl sayısı olmak üzere soğutucu akışkanın Nusselt sayısı Denklem 2.14 ile hesaplanır.

$N u=0,023 \cdot \operatorname{Re}^{0,8} \cdot \operatorname{Pr}^{0,4}$

Nu Nusselt sayısı, D akışkanın aktığı boru çapı ve k 1sı iletim katsayısı olarak ısı taşınım katsayısı h Denklem 2.15 ile hesaplanır.

$h=N u \cdot \frac{k}{D}$

Denklem 2.16 ile toplam 1sı direnç katsayısı hesaplanır. A Alüminyum alüminyum plakanın 1sı transfer alanı, Aekipman ekipmanın 1sı transfer alanı, kalüminyum alüminyum plakanın 1S1 iletim katsayıS1, kekipman ekipmanın 1sı iletim katsayısı, $L_{1}$ alüminyum plakanın kalınlığı, $L_{2}$ ekipmanın kalınlığı, $A_{\text {boru }}$ soğutucu akışkanın aktığı borunun çapıdır.

$R_{\text {toplam }}=\frac{1}{h \cdot A_{\text {boru }}}+\frac{L_{1}}{k_{\text {alüminyum }} \cdot A_{\text {alüminyum }}}+\frac{L_{2}}{k_{\text {ekipman }} \cdot A_{\text {ekipman }}}$

Ekipmanların ortalama sıcaklığı Denklem 2.17 ile, ekipmanlar ile soğutucu akışkan arasındaki sıcaklık farkı Denklem 2.18 ile, ekipmanların sıcaklığı da Denklem 2.19 ile hesaplanır.

$T_{R}=\frac{T_{1, R}+T_{2, R}}{2}$ 
$\Delta T=\dot{Q} \cdot R_{\text {toplam }}$

$T_{\text {ekipman }}=T_{R}+\Delta T$

Isıl kontrolde kullanılan hava çevrimli soğutma sisteminin şeması Şekil 4'te gösterilmektedir. Havanın $10{ }^{\circ} \mathrm{C}$ altında olduğu durumlarda yapılan bypass işlemi şekilde kırmızı oklar ile gösterildiği gibi yapılmaktadır.

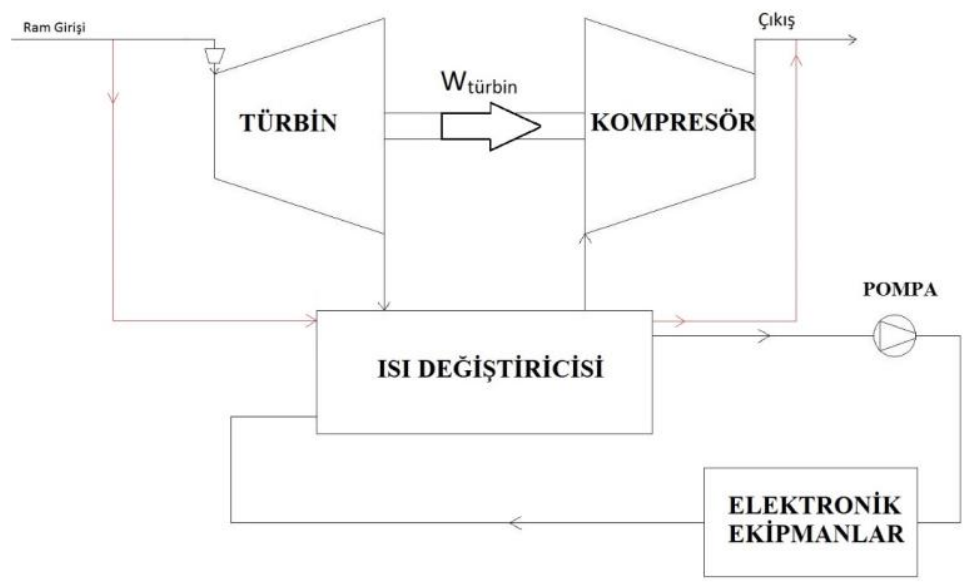

Şekil 4. Hava çevrimli soğutma sisteminin şematik gösterimi

\subsubsection{Isıl Kontrol Sonuçları}

0.4, 0.9 ve 1.2 Mach hizlarında ve $100 \mathrm{~m}$ (300ft), $457 \mathrm{~m}, 914 \mathrm{~m}, 1524 \mathrm{~m}, 2133 \mathrm{~m}, 2743 \mathrm{~m}, 3962$ m, $6096 \mathrm{~m}, 12192 \mathrm{~m}$ yüksekliklerde (sirasiyla $300 \mathrm{ft}, 1500 \mathrm{ft}, 3000 \mathrm{ft}, 5000 \mathrm{ft}, 7000 \mathrm{ft}, 9000 \mathrm{ft}$, $13000 \mathrm{ft}, 20000 \mathrm{ft}, 40000 \mathrm{ft}$ ), sıcak ve soğuk günlerde sıcaklıklar alınarak Matlab Simulink kullanılarak ram havası ile soğutma sistemi için ısıl kontrol yapılmıştır. Tablo 1'de sıcak gün için, Tablo 2'de soğuk gün için sıcaklık değerleri verilmiştir. Bunun yanında ssıl kontrol sonucunda kritik durum için ekipman sıcaklığı $83.91{ }^{\circ} \mathrm{C}$ olarak görülmüş ve yapılan ısıl tasarım ve kontrolün uygun olduğu belirlenmiştir.

Tablo 1. Sıcak günde çevrimdeki havanın sıcaklığı

\begin{tabular}{|c|c|c|c|c|c|c|c|c|}
\hline Feet & & & & Santigrat & rece & & $\mathrm{kg} / \mathrm{s}$ & $\mathrm{kW}$ \\
\hline Yükseklik & Mach & Atmosfer & $\begin{array}{l}\text { Ram } \\
\text { Çıkışı }\end{array}$ & $\begin{array}{c}\text { Türbin } \\
\text { Çıkışı }\end{array}$ & $\begin{array}{c}\text { Eşanjör } \\
\text { Çıkışı }\end{array}$ & $\begin{array}{c}\text { Kompresör } \\
\text { Çıkışı }\end{array}$ & Debi & $\begin{array}{c}\text { Türbin } \\
\text { İşi }\end{array}$ \\
\hline \multirow{4}{*}{300} & 0,4 & 39,43 & 48 & $-25,1$ & 0,8 & 82,9 & 0,2117 & 15,77 \\
\hline & 0,6 & 39,43 & 61,2 & $-15,7$ & 1,7 & 84,2 & 0,3176 & 24,57 \\
\hline & 0,9 & 39,43 & 89,4 & 6,1 & 17,5 & 104,5 & 0,4767 & 39,95 \\
\hline & 1,2 & 39,43 & 128,6 & 36,2 & 44 & 140,14 & 0,6354 & 59,07 \\
\hline
\end{tabular}

Tablo 1. Sıcak gün için çevrimdeki havanın sıcaklığı (devamı) 


\begin{tabular}{|c|c|c|c|c|c|c|c|c|}
\hline \multirow{2}{*}{$\begin{array}{c}\text { Feet } \\
\text { Yükseklik } \\
\end{array}$} & \multirow[b]{2}{*}{ Mach } & \multicolumn{5}{|c|}{ Santigrat Derece } & \multirow{2}{*}{$\begin{array}{l}\mathrm{kg} / \mathrm{s} \\
\mathrm{Debi} \\
\end{array}$} & \multirow{2}{*}{$\begin{array}{c}\text { kW } \\
\begin{array}{c}\text { Türbir } \\
\text { İşi }\end{array} \\
\end{array}$} \\
\hline & & Atmosfer & $\begin{array}{l}\text { Ram } \\
\text { Çıkışı }\end{array}$ & $\begin{array}{c}\text { Türbin } \\
\text { Çıkışı }\end{array}$ & $\begin{array}{c}\text { Eşanjör } \\
\text { Çıkışı }\end{array}$ & $\begin{array}{c}\text { Kompresör } \\
\text { Çıkışı }\end{array}$ & & \\
\hline \multirow{4}{*}{1500} & 0,4 & 36,1 & 46,07 & $-27,5$ & $-0,52$ & 80 & 0,205762 & 15,2 \\
\hline & 0,6 & 36,1 & 58,45 & $-17,8$ & 0 & 81,9 & 0,30864 & 24,3 \\
\hline & 0,9 & 36,1 & 86,27746 & 3,7 & 15,51 & 102,1 & 0,462967 & 37 \\
\hline & 1,2 & 36,1 & 125,2241 & 33,4 & 42,52 & 137,3 & 0,6172 & 56 \\
\hline \multirow{4}{*}{3000} & 0,4 & 32,8 & 42,72594 & -30 & $-2,5$ & 78,3 & 0,202392 & 15,3 \\
\hline & 0,6 & 32,8 & 54,96338 & $-20,4$ & $-2,4$ & 78,7 & 0,303445 & 23,2 \\
\hline & 0,9 & 32,8 & 82,49764 & 0,71 & 12,7 & 98,4 & 0,455186 & 37,2 \\
\hline & 1,2 & 32,8 & 121,0455 & 30,32 & 39,5 & 132,8 & 0,606945 & 55,7 \\
\hline \multirow{4}{*}{5000} & 0,4 & 28,5 & 38,2513 & $-33,5$ & $-3,1$ & 77,6 & 0,182755 & 13,5 \\
\hline & 0,6 & 28,5 & 50,3152 & $-24,2$ & -4 & 76,7 & 0,274148 & 21,7 \\
\hline & 0,9 & 28,5 & 77,4595 & $-3,5$ & 10,4 & 94,8 & 0,411222 & 33,5 \\
\hline & 1,2 & 28,5 & 115,4606 & 26,2 & 36,2 & 128,5 & 0,548296 & 49,2 \\
\hline \multirow{4}{*}{7000} & 0,4 & 24,265 & 33,77643 & $-36,7$ & $-4,2$ & 75,5 & 0,171183 & 12,5 \\
\hline & 0,6 & 24,265 & 45,66703 & $-27,8$ & $-6,1$ & 73,7 & 0,256775 & 19,2 \\
\hline & 0,9 & 24,265 & 72,42077 & $-7,2$ & 7,1 & 91,2 & 0,385162 & 32 \\
\hline & 1,2 & 24,265 & 109,879 & 21,6 & 32,2 & 123,5 & 0,513557 & 46 \\
\hline \multirow{4}{*}{9000} & 0,4 & 19,927 & 29,3018 & $-40,4$ & $-6,1$ & 73,3 & 0,161568 & 12 \\
\hline & 0,6 & 19,927 & 41,01882 & $-31,2$ & $-8,4$ & 70,6 & 0,24235 & 19 \\
\hline & 0,9 & 19,927 & 67,38238 & $-11,3$ & 4,3 & 87,3 & 0,363524 & 30 \\
\hline & 1,2 & 19,927 & 104,2914 & 17,2 & 28,6 & 119,2 & 0,4843 & 43 \\
\hline \multirow{4}{*}{13000} & 0,4 & 11,255 & 20,35217 & $-47,1$ & $-7,5$ & 71,5 & 0,14004 & 11 \\
\hline & 0,6 & 11,255 & 31,72244 & $-38,5$ & $-12,3$ & 65,7 & 0,21007 & 16 \\
\hline & 0,9 & 11,255 & 57,3054 & $-18,8$ & $-1,4$ & 80,2 & 0,315133 & 25 \\
\hline & 1,2 & 11,255 & 93,12175 & 8,9 & 22 & 110,4 & 0,420178 & 37 \\
\hline \multirow{4}{*}{20000} & 0,4 & $-3,2$ & Byl & Pass & 45,8 & 141,2 & 0,112997 & - \\
\hline & 0,6 & $-3,2$ & Byl & Pass & 29,5 & 120,4 & 0,169497 & - \\
\hline & 0,9 & $-3,2$ & Byl & Pass & 18,6 & 105 & 0,254246 & - \\
\hline & 1,2 & $-3,2$ & Byl & Pass & 13,2 & 98,8 & 0,338997 & - \\
\hline \multirow{4}{*}{40000} & 0,4 & $-42,1$ & Byl & Pass & 63,5 & 164,4 & 0,052343 & - \\
\hline & 0,6 & $-42,1$ & By & Pass & 28,3 & 118,6 & 0,078523 & - \\
\hline & 0,9 & $-42,1$ & Byl & Pass & 4,8 & 88,2 & 0,117785 & - \\
\hline & 1,2 & $-42,1$ & Byl & Pass & $-6,7$ & 72,6 & 0,157047 & - \\
\hline
\end{tabular}

Tablo 2. Soğuk günde çevrimdeki havanın sıcaklığı 


\begin{tabular}{|c|c|c|c|c|c|c|c|c|}
\hline \multirow{2}{*}{$\begin{array}{c}\text { Feet } \\
\text { Yükseklik }\end{array}$} & \multirow[b]{2}{*}{ Mach } & \multicolumn{5}{|c|}{ Santigrat Derece } & \multirow{2}{*}{$\begin{array}{l}\mathrm{kg} / \mathrm{s} \\
\mathrm{Debi}\end{array}$} & \multirow{2}{*}{$\begin{array}{c}\text { kW } \\
\begin{array}{c}\text { Türbin } \\
\text { İşi }\end{array}\end{array}$} \\
\hline & & Atmosfer & $\begin{array}{l}\text { Ram } \\
\text { Çıkışı }\end{array}$ & $\begin{array}{l}\text { Türbin } \\
\text { Çıkışı }\end{array}$ & $\begin{array}{l}\text { Eşanjör } \\
\text { Çıkışı }\end{array}$ & $\begin{array}{c}\text { Kompresör } \\
\text { Çıkışı }\end{array}$ & & \\
\hline \multirow{4}{*}{300} & 0,4 & $-51,2$ & \multicolumn{2}{|c|}{ ByPass } & $-24,8$ & ByPass & 0,2117 & - \\
\hline & 0,6 & $-51,2$ & \multicolumn{2}{|c|}{ ByPass } & $-33,5$ & ByPass & 0,3176 & - \\
\hline & 0,9 & $-51,2$ & \multicolumn{2}{|c|}{ ByPass } & $-39,3$ & ByPass & 0,4765 & - \\
\hline & 1,2 & $-51,2$ & \multicolumn{2}{|c|}{ ByPass } & $-42,2$ & ByPass & 0,635454 & - \\
\hline \multirow{4}{*}{1500} & 0,4 & $-45,1$ & \multicolumn{2}{|c|}{ ByPass } & 2 & ByPass & 0,205766 & - \\
\hline & 0,6 & $-45,1$ & \multicolumn{2}{|c|}{ ByPass } & $-27,3$ & ByPass & 0,30864 & - \\
\hline & 0,9 & $-45,1$ & \multicolumn{2}{|c|}{ ByPass } & $-33,3$ & ByPass & 0,462974 & - \\
\hline & 1,2 & $-45,1$ & \multicolumn{2}{|c|}{ ByPass } & $-36,2$ & ByPass & 0,6171 & - \\
\hline \multirow{4}{*}{3000} & 0,4 & $-39,4$ & \multicolumn{2}{|c|}{ ByPass } & $-11,8$ & ByPass & 0,202308 & - \\
\hline & 0,6 & $-39,4$ & \multicolumn{2}{|c|}{ ByPass } & $-20,8$ & ByPass & 0,303462 & - \\
\hline & 0,9 & $-39,4$ & \multicolumn{2}{|c|}{ ByPass } & $-26,9$ & ByPass & 0,455193 & - \\
\hline & 1,2 & $-39,4$ & \multicolumn{2}{|c|}{ ByPass } & $-29,7$ & ByPass & 0,606925 & - \\
\hline \multirow{4}{*}{5000} & 0,4 & $-28,3$ & \multicolumn{2}{|c|}{ ByPass } & 2,1 & ByPass & 0,182764 & - \\
\hline & 0,6 & $-28,3$ & \multicolumn{2}{|c|}{ ByPass } & $-7,7$ & ByPass & 0,274147 & - \\
\hline & 0,9 & $-28,3$ & \multicolumn{2}{|c|}{ ByPass } & $-14,5$ & ByPass & 0,411222 & - \\
\hline & 1,2 & $-28,3$ & \multicolumn{2}{|c|}{ ByPass } & $-17,8$ & ByPass & 0,548296 & - \\
\hline \multirow{4}{*}{7000} & 0,4 & $-28,3$ & \multicolumn{2}{|c|}{ ByPass } & 4,4 & ByPass & 0,171182 & - \\
\hline & 0,6 & $-28,3$ & \multicolumn{2}{|c|}{ ByPass } & $-6,6$ & ByPass & 0,256775 & - \\
\hline & 0,9 & $-28,3$ & & ass & $-13,5$ & ByPass & 0,385163 & - \\
\hline & 1,2 & $-28,3$ & & ass & $-17,1$ & ByPass & 0,513551 & - \\
\hline & 0,4 & $-28,3$ & & ass & 6,3 & ByPass & 0,161565 & - \\
\hline תחم0 & 0,6 & $-28,3$ & & ass & $-5,2$ & ByPass & 0,24233 & - \\
\hline 3000 & 0,9 & $-28,3$ & & ass & $-12,7$ & ByPass & 0,363524 & - \\
\hline & 1,2 & $-28,3$ & & ass & $-16,5$ & ByPass & 0,4848 & - \\
\hline & 0,4 & -31 & & ass & 9,4 & ByPass & 0,14005 & - \\
\hline 13000 & 0,6 & -31 & & ass & $-3,6$ & ByPass & 0,21008 & - \\
\hline 13000 & 0,9 & -31 & & ass & $-12,4$ & ByPass & 0,315133 & - \\
\hline & 1,2 & -31 & & ass & $-16,7$ & ByPass & 0,420178 & - \\
\hline & 0,4 & -43 & & ass & 4,8 & ByPass & 0,112998 & - \\
\hline 20000 & 0,6 & -43 & & ass & $-11,3$ & ByPass & 0,169497 & - \\
\hline 20000 & 0,9 & -43 & & ass & $-22,2$ & ByPass & 0,254246 & - \\
\hline & 1,2 & -43 & & ass & $-27,6$ & ByPass & 0,338997 & - \\
\hline
\end{tabular}

Tablo 2. Soğuk günde çevrimdeki havanın sıcaklı̆ğ (devamı) 


\begin{tabular}{|c|c|c|c|c|c|c|c|c|}
\hline Yükseklik & Mach & Atmosfer & $\begin{array}{l}\text { Ram } \\
\text { Çıkışı }\end{array}$ & $\begin{array}{c}\text { Türbin } \\
\text { Çıkışı }\end{array}$ & $\begin{array}{c}\text { Eşanjör } \\
\text { Çıkışı }\end{array}$ & $\begin{array}{c}\text { Kompresör } \\
\text { Çıkışı }\end{array}$ & Debi & $\begin{array}{c}\text { Türbin } \\
\text { İşi }\end{array}$ \\
\hline \multirow{4}{*}{40000} & 0,4 & -64 & \multicolumn{2}{|c|}{ ByPass } & 40,5 & ByPass & 0,052348 & - \\
\hline & 0,6 & -64 & \multicolumn{2}{|c|}{ ByPass } & 5,3 & ByPass & 0,078523 & - \\
\hline & 0,9 & -64 & \multicolumn{2}{|c|}{ ByPass } & $-18,2$ & ByPass & 0,117785 & - \\
\hline & 1,2 & -64 & \multicolumn{2}{|c|}{ ByPass } & $-29,7$ & ByPass & 0,157047 & - \\
\hline
\end{tabular}

Tablo 3. Soğutucu akışkan R-236fa'nın sistemdeki değerleri

\begin{tabular}{lccccc}
\hline & $\begin{array}{c}\text { Eşanjöre Giriş̧ } \\
\text { Sıcaklığı }\left({ }^{\circ} \mathbf{C}\right)\end{array}$ & $\begin{array}{c}\text { Eşanjörden Çıkış } \\
\text { Sıcaklı̆ııı }\left({ }^{\circ} \mathrm{C}\right)\end{array}$ & Kütle Debisi(kg/s) & $\begin{array}{c}\text { Yayılan Isı } \\
(\mathbf{k W})\end{array}$ \\
\hline $\mathrm{R}-236 \mathrm{fa}$ & 41,4 & 48 & 0,435 & 5 &
\end{tabular}

Yapılan 1sıl kontrolde atmsfer şartları ve uçak hızının, sistem üzerinde hayati öneme arz ettiği görülmüştür. Kontrol sonucunda, soğuk gün için uçak hızı arttıkça sistemin giriş ve çıkışı arasındaki sıcaklık farkının, uçak düşük Machlarda iken azaldığı fakat mach sayısı arttıkça (Ses hızına yaklaştıkça) arttığı, bunun yanı sıra türbin işinin Mach'a bağlı olmadan hız arttıkça sürekli arttığı görülmüştür. Sıcak güne bakıldığında ise, hem türbin işinin hem de sıcaklık farkının mach sayısından bağımsız olarak arttığı görülmüştür. İkinci sonuç ise, sisteme giren ve çıan havanın sıcaklık farkının yüksekliğe ilişkisidir. Uçağın irtifası arttıkça sıcak ve soğuk günde sıcaklık farkının arttığ 1 görülmüştür. Hava yoğunluğunun yükseklikle beraber çok düşmesi ve bunun sonucunda sisteme giren havanın debisinin düşmesi, türbin işinin yükseklik arttıkça düşmesine sebep olmuştur.

\section{Sonuçlar}

Bu çalışma sonucunda uçakta kullanılan, $5 \mathrm{~kW}$ 1sı üretimi olan ve içerisinde bir faydalı yük bulunduran elektronik podun 1sıl kontrolü yapılmış̧ır. Kontrol için mümkün olan üç metot düşünüldüğü zaman, daha basit olan, bakımı kolay ve maliyeti daha düşük olan hava çevrimli soğutma sistemi seçilmiştir. Havacılık standartları göz önüne alınarak belirlenen soğuk ve sicak günlerde, önerilen sistemdeki sıcaklık değerleri Matlab Simulink ile belirlenmiştir. Soğuk günde yükseklik çok fazla olduğunda hava sıcaklığı da çok düşük olacağ 1 için elektronik ekipmanların çalışmama riskinin ortaya çıktığı düşünüldüğünde bir 1sitıc1 yoluyla bunun önleneceği öngörülmektedir. Uçak deniz seviyesinde çalışırken herhangi bir hava girişi olmayacağ sisteme gereken havanın fan yardımı ile alacağı da öngörülmüştür. Uçak ses hızına yakın ya da ses hızından yüksek hızda uçtuğunda sistemin daha verimli çalıştığı tespit edilmiştir. Uçağın uçuş yüksekliği arttıkça da sıcaklığın ciddi manada düştüğü tespit edilmiş ve türbin-kompresör sisteminin çalışmasına gerek duyulmamış, hava 1sı değiştiricisine doğrudan girerek soğutma sağlanmıştır.

Isıl kontrol neticesinde ekipmanların sıcaklıklarının, istenilen aralıkta olduğu, sistemin belirlenen yükseklik ve hızlarda düzgün ve verimli çalıştı̆̆ tespit edilmiştir.

\section{Kaynaklar}


[1] T. J. Kazan, Design, Analysis And Test Of An Air Cycle Environmental Control System For An Airborne Electronıcs Equipment Pod, Department of Mechanical Engineering California State University, Master Science Thesis, 1996.

[2] S. Akçay, N. Sozbir, A. Aydemir, E.A. Başeşme, "Askeri hava araçlarindaki harici yüklerde kullanilan çevresel kontrol sistemlerinin incelenmesi," pp. 1-7, 2016.4

[3] D. C. Price, "Thermal Management of Military Fighter Aircraft Electro-optics Pod," pp. 68, 2003.

[4] Z. Wu and R. Du, "Design and experimental study of a miniature vapor compression refrigeration system for electronics cooling," Appl. Therm. Eng., vol. 31, no. 2-3, pp. 385390, 2011.

[5] Z. Shavit and Y. Nishri, "On the Development of Air Cycle Machine for Cooling Airborne Pods," 2012.

[6] R. P. Scaringe, "A compact thermal control system for aircraft avionics pod cooling," pp. 1492-1496.

[7] R. Agrawal, S. Mada, "Hybrid Environmental Control System for Military Aircraft", Global Journal of Researches in Engineering Electrical and Electronics Engineering, vol.13, 2013

[8] I. de Boer, "The Cooling of a Pod-mounted Avionic System," 1976.

[9] M. Engelhardt, S. Principal, E. Ii, and M. Engineering, "Thermal Control of an Airborne Electronics Bay,” vol. i, no. January, pp. 1-16, 2007.

[10] R-236fa Specifications, Climalife, 2016

[11] U.S. Standard Atmosphere Air Properties, 1976.

[12] Y. Çengel, Isı ve Kütle Transferi, Üçüncü Basım, Güven Bilimsel,2012.

[13] Environmental Extremes for the Design of Airborne Equipment, MIL-STD-210A, 1957 